\title{
Dynamic thiol-disulphide homeostasis in the etiopathogenesis of obstructive jaundice
}

\author{
Fadime Gullu Haydar ${ }^{1}$, Yavuz Otal ${ }^{1}$, GAMZE AVCIOĞLU², Alp Şener ${ }^{3}$, Selda Kidak \\ Ozkaya $^{1}$, Yunus halil Polat ${ }^{1}$, Şervan Gökhan ${ }^{3}$, and Özcan Erel ${ }^{4}$ \\ ${ }^{1}$ Ankara City Hospital \\ ${ }^{2}$ Affiliation not available \\ ${ }^{3}$ Ankara Yildirim Beyazit University Faculty of Medicine \\ ${ }^{4}$ Ankara Yildirim Beyazit Universitesi Tip Fakultesi
}

February 20, 2021

\begin{abstract}
ABSTRACT Background:Metabolic changes seen after obstructive jaundice increase the load of oxidative stress. The thioldisulphide homeostasis (TDB) has a vital importance as oxidatice stress biomarker. Aim: The aim of present study is to investigate the dynamic thiol-disulphide homeostasis in patients diagnosed with obstructive jaundice and to compare the dynamic thiol-disulphide homeostasis with ischemia modified albumin. Study design: A total of 146 participants who were admitted to emergency department and who consisted of 69 patients and 77 healthy volunteers, were included in the study. Detailed blood samples were obtained from the patients at the time of admission. Methods: Thiol / disulphide levels were examined using a novel method developed by Erel and Neselioglu on the patients diagnosed with obstructive jaundice during the admission. Data were evaluated in computer system. Results: The levels of total thiol $(\mathrm{p}=0.025)$ and native thiol $(\mathrm{p}$ $=0.023$ ) were statistically significantly lower in the patient with obstructive jaundice than in the control group. It was observed that there was a significant negative correlation between the native thiol levels and the ALP $(r=-0.262, \mathrm{p}<0.01)$, urea $(\mathrm{r}$ $=-0.313, \mathrm{p}<0.01)$, total bilirubin $(\mathrm{r}=-0.388, \mathrm{p}<0.01)$, direct bilirubin $(\mathrm{r}=-0.351, \mathrm{p}<0.01)$ levels. At the same time, the level of disulphide $(\mathrm{p}=0.235$ ) was lower in the patient group than in the control group but not statistically significant. It was found that the ischemia modified albumin (IMA) values were lower in the control group than the obstructive jaundice group ( $\mathrm{p}=$ 0.03). Conclusion: Total thiol, native thiol and IMA levels decrease in obstructive jaundice pathogenesis.
\end{abstract}

\section{Hosted file}

$T \backslash$ selectlanguage $\{\text { polish }\}_{1} \backslash$ selectlanguage $\{$ english\}kanma \selectlanguage\{polish\}I $\backslash$ selectlanguage\{english\}. available at https://authorea.com/users/396704/articles/509974-dynamic-thiol-disulphidehomeostasis-in-the-etiopathogenesis-of-obstructive-jaundice 

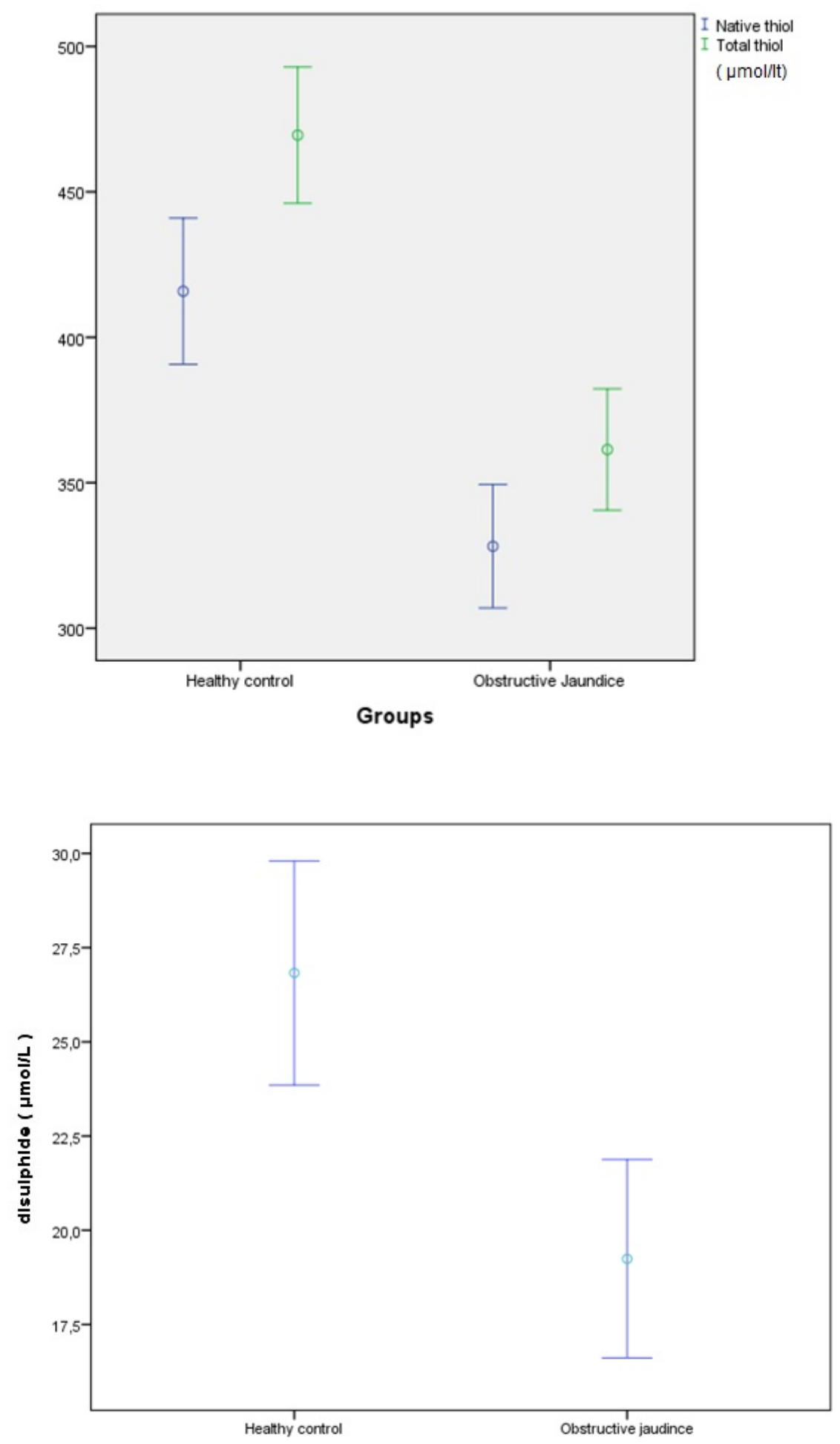


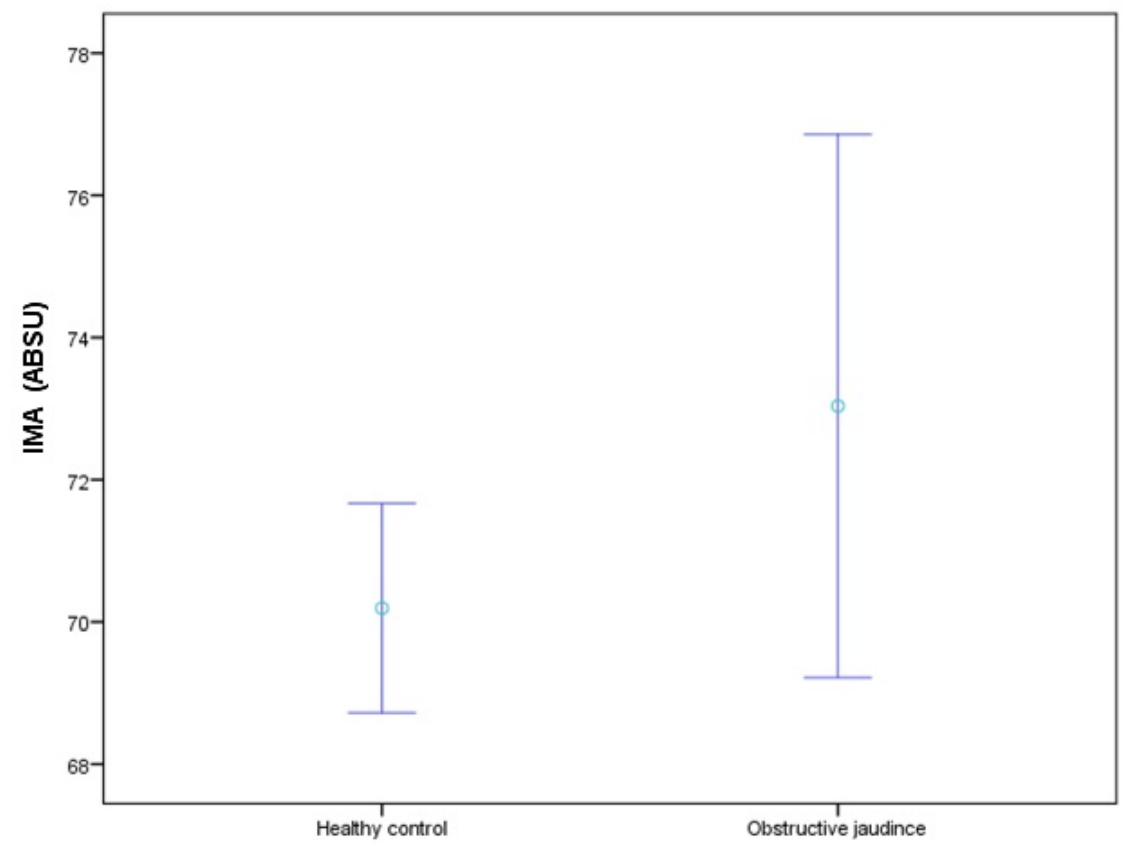

\section{Hosted file}

tablo1.pdf available at https://authorea.com/users/396704/articles/509974-dynamic-thioldisulphide-homeostasis-in-the-etiopathogenesis-of-obstructive-jaundice

\section{Hosted file}

Tablo 2.pdf available at https://authorea.com/users/396704/articles/509974-dynamic-thioldisulphide-homeostasis-in-the-etiopathogenesis-of-obstructive-jaundice

\section{Hosted file}

Tablo 3.pdf available at https://authorea.com/users/396704/articles/509974-dynamic-thioldisulphide-homeostasis-in-the-etiopathogenesis-of-obstructive-jaundice 